\title{
Comparing Clinical and Economic Outcomes Associated with Early Initiation of Combination Therapy of an Alpha Blocker and Dutasteride or Finasteride in Men with Benign Prostatic Hyperplasia in the United States
}

Maral DerSarkissian, PhD; Yongling Xiao, PhD; Mei Sheng Duh, MPH, ScD;

Patrick Lefebvre, MA; Andrine R. Swensen, MS, PhD; and Christopher F. Bell, MS

\section{ABSTRACT}

BACKGROUND: Benign prostatic hyperplasia (BPH) is a common disease in men that is characterized by lower urinary tract symptoms. Pharmacologic treatment with alpha blockers (ABs) and 5-alpha reductase inhibitors (5ARIs) is recommended to alleviate symptoms, prevent disease progression that can lead to complications, and reduce health care costs.

OBJECTIVE: To compare clinical, economic, and health care resource utilization outcomes among BPH patients treated with early continuous combination $A B$ and $5 A R I$ therapy (dutasteride vs. finasteride) using administrative claims data from the United States.

METHODS: A retrospective analysis of administrative claims data from 2003-2013 was conducted to compare outcomes between patients with claims for early combination therapy with dutasteride $+A B$ and patients with claims for early finasteride $+A B$. The study population included males aged older than 50 years with at least 1 medical claim with a diagnosis of BPH and pharmacy dispensing for $A B$ and 5ARI therapies. Outcomes included acute urinary retention (AUR), prostate-related surgery, clinical progression, medical and pharmacy costs, and health care resource utilization. Inverse probability of treatment (IPT) weighted Cox proportional hazards, linear, and Poisson regression models were used to assess the association between outcomes and early combination therapy as appropriate.

RESULTS: A total of 2,778 patients were included in the early finasteride + $A B$ treatment cohort, and 4,125 patients were included in the early dutasteride $+A B$ cohort. Dutasteride users were younger than finasteride users (mean age: 64.8 vs. 67.5 years, $P<0.001$ ) and had a greater mean number of urologist visits (10.7 vs. $7.9, P<0.001)$ during baseline. After adjusting for confounding using IPT weighting, no statistically significant difference was observed between dutasteride and finasteride for AUR (hazard ratio $[\mathrm{HR}]=0.845,95 \% \mathrm{Cl}=0.660-1.070, P=0.1643)$, prostate-related surgery $(\mathrm{HR}=0.806,95 \% \mathrm{Cl}=0.568-1.171, P=0.2525)$, and clinical progression $(\mathrm{HR}=0.834,95 \% \mathrm{Cl}=0.663-1.043, P=0.1122)$. While dutasteride was associated with higher pharmacy costs per month (adjusted monthly cost difference $=\$ 79,95 \% \mathrm{Cl}=\$ 45-\$ 105)$, total all-cause medical costs were not significantly different between the 2 cohorts (adjusted monthly cost difference $=-\$ 44,95 \% \mathrm{Cl}=-\$ 110-\$ 22)$.

CONCLUSIONS: Clinical and economic outcomes were similar between the early dutasteride $+A B$ and early finasteride $+A B$ cohorts, with no statistically significant differences detected.

J Manag Care Spec Pharm. 2016;22(10):1204-14

Copyright $\odot 2016$, Academy of Managed Care Pharmacy. All rights reserved.

\section{What is already known about this subject}

Benign prostatic hyperplasia (BPH) is a common progressive disease in men associated with lower urinary tract symptoms, acute urinary retention, and prostate-related surgery, which contribute to increased health care resource utilization and costs of managing the condition.

$\mathrm{BPH}$ is managed pharmacologically by alpha blockers (ABs) and 5-alpha reductase inhibitors (5ARIs)

Recent observational studies and clinical trials support the use of combination therapy with an AB and 5ARI in patients with BPH.

\section{What this study adds}

After adjustment, comparisons between the early dutasteride $+\mathrm{AB}$ and early finasteride $+\mathrm{AB}$ cohorts revealed lower risk of acute urinary retention, prostate-related surgery, and clinical progression among patients treated with dutasteride, although these differences did not reach statistical significance.

Patients with BPH treated with early combination dutasteride $+\mathrm{AB}$ therapy had higher pharmacy costs, but total all-cause health care costs were not significantly different between patients treated with dutasteride versus finasteride.

B enign prostatic hyperplasia (BPH) is one of the most common nonmalignant chronic diseases in men aged 50 years or older. It is a slowly progressive disease characterized by urinary obstruction and significant lower urinary tract symptoms. ${ }^{1-3}$ BPH symptoms, such as urinary frequency and urgency, are caused by unregulated growth of the prostate gland. ${ }^{1,4-6}$ Clinical progression of BPH can lead to significant medical complications, such as acute urinary retention (AUR) and BPH-related surgery, ${ }^{7-10}$ contributing to an estimated $\$ 4$ billion in BPH-related medical costs each year. ${ }^{11}$

Watchful waiting, pharmacologic therapy, minimally invasive procedures, and surgery are currently used to manage $\mathrm{BPH}$ based on the extent to which the symptoms are bothersome and severe. ${ }^{12} \mathrm{BPH}$ is pharmacologically managed through 2 main categories of drugs: $\alpha$-adrenergic blockers (ABs) and 


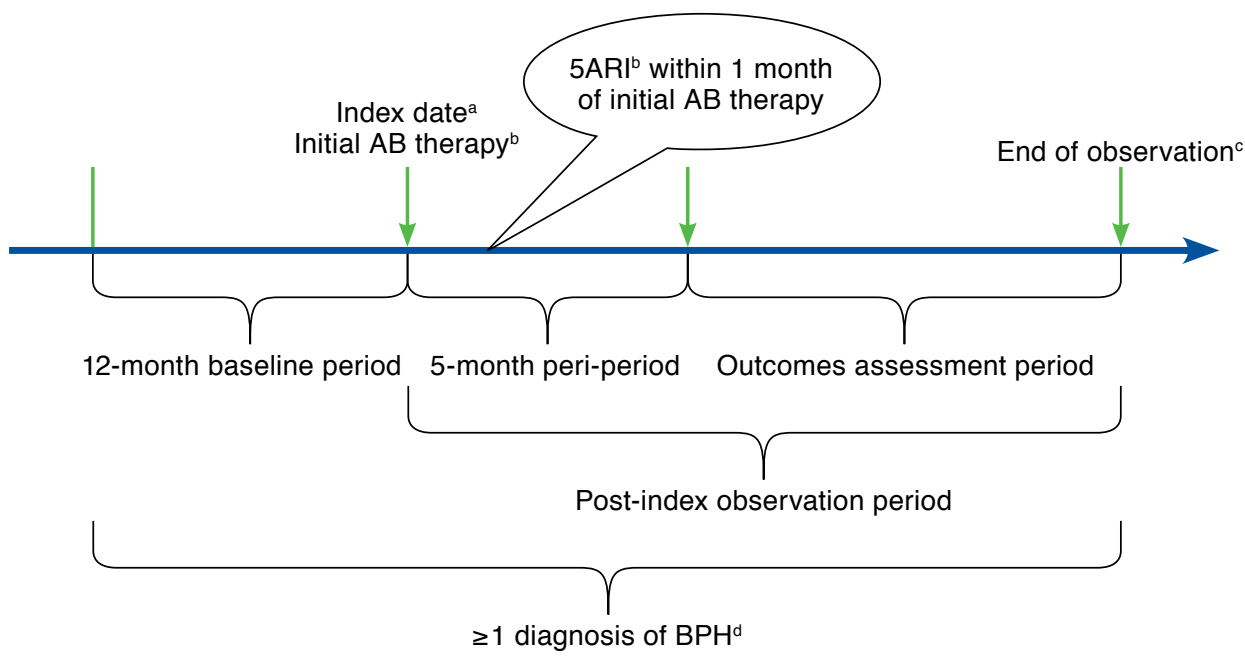

aThe earliest possible index date was January 1, 2004.

${ }^{b} A B$ therapy included alfuzosin, doxazosin, tamsulosin, and terazosin. 5ARI therapy included finasteride and dutasteride. Note that some patients were on Jalyn, a combination $A B+5 A R I$ treatment.

'The end of observation for each patient was defined as the earliest of the following dates: a gap of 60 days between AB pharmacy claims or 5ARI pharmacy claims, health plan disenrollment, death, or the end of data availability to assess patient outcomes.

dICD-9-CM codes 222.2x and 600.xx.

$A B=$ alpha blocker; $B P H=$ benign prostatic hyperplasia; ICD-9-CM = International Classification of Diseases, Ninth Revision, Clinical Modification; 5ARI=5-alpha reductase inhibitor.

5-alpha reductase inhibitors (5ARIs)., ${ }^{1,713-16}$ ABs relax the smooth muscle of the prostate and bladder neck and offer rapid symptom improvement, ${ }^{17}$ although they do not prevent progressive prostate enlargement. ${ }^{2,14,18}$ On the other hand, 5ARIs inhibit the 5-alpha reductase enzyme and prevent the conversion of testosterone to dihydroxytestosterone, thus shrinking the prostate. ${ }^{1,14,15}$ Finasteride (which inhibits the type 2 isoenzyme only) and dutasteride (which inhibits type 1 and type 2 isoenzymes) are approved 5ARIs prescribed in the United States.

The complementary effects of ABs and 5ARIs, in terms of immediate symptom control from $A B s$ and reduction in long-term risk of disease progression from 5ARIs, make them suitable components of combination therapy for some patients with BPH. ${ }^{19}$ Randomized clinical trials, such as the Medical Therapy of Prostatic Symptoms (MTOPS) and Combination of Avodart and Tamsulosin (COMBAT) studies, ${ }^{14,20}$ have demonstrated that combination therapy is significantly more effective than either component alone in reducing symptoms and lowering rates of AUR and BPH-related surgery among patients..$^{20-22}$

Observational studies comparing combination therapy $(5 \mathrm{ARI}+\mathrm{AB})$ to monotherapy with either individual therapy confirmed clinical trial findings that combination therapy is more effective in preventing disease progression and reducing symptoms than monotherapy. ${ }^{12,23-25}$ A recent clinical trial found that a fixed-dose combination of dutasteride and tamsulosin (an AB) given with lifestyle advice to men with moderate BPH symptoms resulted in rapid and sustained improvements in symptom control and reduced risk of clinical progression, compared with watchful waiting and initiation of tamsulosin per protocol. ${ }^{26}$ Furthermore, studies have suggested that earlier initiation of combination therapy was associated with significant reductions in clinical progression, AUR rates, surgery rates, and BPH-related medical costs compared with delayed initiation..$^{12,20,23}$ While the use of combination therapy has increased over time,${ }^{27}$ no real-world studies have assessed differences in outcomes among patients on combination therapy with respect to individual 5ARIs (i.e., dutasteride vs. finasteride).

To address this gap in the literature, this study compared the clinical and economic outcomes associated with early combination therapy with dutasteride $+\mathrm{AB}$ versus finasteride $+\mathrm{AB}$ by analyzing medical and pharmacy administrative claims data from patients in the United States.

\section{Methods}

\section{Study Design}

A retrospective longitudinal cohort study was conducted using health care administrative claims, including medical, pharmacy, and enrollment data, to assess BPH-related outcomes, 
costs, and health care resource utilization in patients diagnosed with BPH and treated with early combination 5ARI and AB therapy. Data from the MarketScan Commercial Claims and Encounters and Medicare Supplemental Databases were obtained from Truven Health Analytics and used for this analysis. The data encompassed employees, their spouses, and their dependents covered by employer-sponsored private health insurance and represented more than 100 large employers and 12 unique health plans throughout the United States. Commercial claims data were available from 2003-2013, with Medicare claims data available from 2006-2013.

Figure 1 graphically depicts the study design scheme used. The date of each patient's first claim for an $A B$ therapy was defined as the index date. A 5-month peri-period after the index date was taken into account in order to allow for the 4-6 months of treatment required for 5ARIs to affect the prostate. The end of follow-up for each patient was defined as the earliest of the end of data availability to assess outcomes, a gap of 60 days or more between AB pharmacy claims or 5ARI pharmacy claims, health plan disenrollment, or death.

\section{Sample Selection}

The study population included men aged 50 years or older with at least 1 medical claim with a primary or secondary diagnosis for $\mathrm{BPH}$ or an enlarged prostate, defined as International Classification of Diseases, Ninth Revision, Clinical Modification (ICD-9-CM) diagnosis codes 222.2x (benign neoplasm of prostate) or 600.xx (hyperplasia of prostate). Patients were also required to initiate combination $A B$ and 5ARI therapy (i.e., 5ARI within 1 month after the initial $A B$ prescription) and to be continuously eligible to receive medical and pharmacy services 12 months before (i.e., the baseline period) and 12 months following (i.e., the observation period) the initial $\mathrm{AB}$ prescription.

Patients were excluded from the study population if they had 1 or more medical claims with a primary or secondary diagnosis of prostate cancer (ICD-9-CM diagnosis codes 185, $198.82,233.4,236.5,239.5$, or v10.46) or bladder cancer (ICD-9-CM diagnosis codes 188, 198.1, 223.3, 233.7, 239.4, or v10.51), or had a prescription for finasteride $1 \mathrm{mg}$ (Propecia) for the treatment of male-pattern baldness during the 12-month pre-index baseline period. In order to ensure that patients in the study population were in early stages of disease progression (i.e., not in advanced stages of disease), patients with a history of AUR or prostate surgery during the baseline period or within the 5 month peri-period after the index date were excluded from the study population. This method is similar to the approach used by Kruep et al. (2011) ${ }^{23}$ in their study of early combination treatment of BPH and is reflective of clinical efficacy information provided in the prescribing information of 5ARIs. ${ }^{28,29}$ Furthermore, patients with a claim for a 5ARI before the initial $A B$ claim, a gap of more than 60 days between $A B$ pharmacy claims or 5ARI pharmacy claims during the periperiod (imposed to ensure that patients were on treatment for the duration of the study and that their outcomes would be attributable to the combination therapy), or pharmacy claims for dutasteride and finasteride at any point during the followup period were also excluded.

\section{Study Measures}

Primary endpoints in this study included clinical, economic, and health care resource utilization outcomes. The clinical outcomes of AUR, prostate-related surgery, and clinical progression were evaluated after the 5-month peri-period. AUR and prostate-related surgery were defined by the presence of at least 1 medical claim with a diagnosis of AUR (ICD-9-CM codes 788.2 [excluding 788.21] and 599.6) and procedure code for prostate-related surgery (Current Procedural Terminology codes 52601, 52612, 52614, 52620, 52640, 52647, 52648, $55801,55821,55831,52850,52852$, and 52853), respectively. Clinical progression was a composite variable based on the presence of a medical claim for AUR or prostate surgery. The incidence and number of urinary symptoms based on the International Prostate Symptom Score (I-PSS), including incomplete emptying (ICD-9-CM code 788.21), urinary frequency (ICD-9-CM code 788.41), urination intermittency (ICD-9-CM code 788.64), urination urgency (ICD-9-CM code 788.63), weak stream (ICD-9-CM code 788.62), straining in urination (ICD-9-CM code 788.65), and nocturia (ICD-9-CM code 788.43) were also evaluated.

All-cause and BPH-related total, medical, and pharmacy costs were estimated from medical and pharmacy claims. BPHrelated medical costs were defined as costs associated with medical claims with a primary or secondary diagnosis of BPH, while BPH-related pharmacy costs were defined as any costs associated with pharmacy claims for ABs and 5ARIs. Medical costs were evaluated after the 5-month peri-period, and pharmacy costs were evaluated from the index date until the end of follow-up. Because this study was conducted from a payer perspective, the cost data represent actual dollar amounts reimbursed by the payer. All cost estimates were adjusted to 2013 U.S. dollars using the medical care component of the Consumer Price Index and were reported per patient per month (PPPM) to account for different lengths of observation among study patients. Frequency rates of inpatient (and length of stay), outpatient, emergency room, and other ancillary medical services visits were also evaluated after the 5-month periperiod and reported on a PPPM basis to estimate health care resource utilization.

Demographic, economic, and clinical characteristics were evaluated during the 12-month pre-index baseline period and included age, geographic region, insurance type, year of index date, clinical characteristics, and health care costs. The Quan-Charlson Comorbidity Index (CCI), ${ }^{30,31}$ type of index 
$\mathrm{AB}$ therapy, incidence and number of I-PSS symptoms, BPH stage, presence of hematuria, bladder dysfunction, urinary incontinence, bladder stones, and number of visits to a urologist were reported as baseline clinical characteristics. BPH staging assigned patients to 1 of 7 disease severity stages using the Thomson Medstat Disease Staging system that is based on ICD-9-CM diagnosis codes in the 6 months prior to the initiation of an AB. ${ }^{32}$ Clinical characteristics and health care costs were also assessed during the peri-period.

\section{Statistical Analysis}

Patient characteristics, baseline covariates, and outcomes were described using means, standard deviations, and medians for continuous variables and frequency distributions for categorical variables. Statistical comparisons between the early dutasteride $+\mathrm{AB}$ group and the early finasteride $+\mathrm{AB}$ group were conducted using chi-square tests (and Fisher's exact test for covariates with small cell sizes) for categorical variables and Wilcoxon Mann-Whitney nonparametric tests for continuous variables. A $P$ value of $<0.05$ was considered statistically significant.

Inverse probability of treatment (IPT) weighted regression models were used to assess the effect of early combination therapy on clinical, economic, and health care resource utilization outcomes while adjusting for confounding between the 2 groups. IPT weights, defined as the inverse of the conditional probability of receiving one's own treatment, ${ }^{33}$ were calculated for each member of the early dutasteride $+\mathrm{AB}$ and early finasteride $+\mathrm{AB}$ cohorts. A pooled logistic regression model was used to estimate the propensity score (PS), or each patient's probability of receiving the treatment as a function of measured baseline covariates. Covariates included in the PS model are shown in the Appendix (available in online article). IPT weights were then calculated as the inverse of patients' estimated probability of treatment, that is, weights were calculated as $1 \div \mathrm{PS}$ for the early dutasteride $+\mathrm{AB}$ group and as $1 \div(1-\mathrm{PS})$ for the early finasteride $+A B$ group. Normalized unstabilized weights were constructed by dividing each patient's IPT weight by the overall mean IPT weight and were also examined to check for extreme values. Weighting created a pseudopopulation in which the distributions of covariates included in the PS model were balanced between the dutasteride $+\mathrm{AB}$ and finasteride + $\mathrm{AB}$ cohorts.

Weighted regression models were used to estimate the association between 5ARI therapy and the study outcomes, adjusting for baseline confounding. Specifically, mean cost differences and incidence rate ratios for the impact of 5ARI therapy (dutasteride vs. finasteride) on direct health care costs or health care resource utilization were estimated using weighted linear and Poisson regression models, respectively. Weighted Cox proportional hazards models were used to examine the association between early dutasteride $+\mathrm{AB}$ therapy and time to first event for the clinical outcomes of AUR, prostate-related surgery, and clinical progression, compared with early finasteride $+A B$ therapy. To account for variation in the weights, a nonparametric bootstrap procedure was used to calculate confidence intervals and $P$ values based on 499 resamples of the analytical dataset for all outcomes. All statistical analyses were carried out using SAS, version 9.3 (SAS Institute, Cary, NC).

\section{Sensitivity Analysis}

In addition to the main analysis previously described, a sensitivity analysis was conducted to build a study sample in which the final inclusion criterion of continuous enrollment for 12 months after the index date was not applied to avoid introducing a potential survival bias. All descriptive and statistical analyses were repeated for this sensitivity analysis study sample.

\section{Results}

Figure 2 shows the identification of the study population. In the early finasteride $+\mathrm{AB}$ treatment cohort, 2,778 patients were included, and 4,125 patients were included in the early dutasteride $+\mathrm{AB}$ cohort. Baseline characteristics of the dutasteride and finasteride treatment cohorts are reported in Table 1. Dutasteride users were, on average, younger than finasteride users (64.8 years vs. 67.5 years, $P<0.001$ ) and had a lower mean CCI score ( 0.8 vs. 1.0, $P<0.001$ ). In addition, dutasteride patients had a greater mean number of urologist visits (10.7 vs. $7.9, P<0.001)$ and a higher proportion of claims associated with I-PSS symptoms during baseline. The mean duration of follow-up was shorter among patients treated with dutasteride compared with patients treated with finasteride (365 days vs. 421 days, $P<0.001$ ).

Unadjusted descriptive statistics for study outcomes are presented in Table 2. Before adjustment for potential confounders, fewer dutasteride users developed AUR (3.3\% vs. $4.6 \%$, $P=0.0061)$ and clinical progression ( $4.8 \%$ vs. $6.4 \%, P=0.0032)$ during the follow-up period compared with finasteride users, but no difference was seen in the crude rate of prostate surgery (2.1\% vs. $2.6 \%, P=0.1223$ ). Unadjusted mean all-cause pharmacy costs PPPM were significantly higher in the dutasteride cohort ( $\$ 441$ vs. $\$ 354, P<0.0001$ ); however, these were offset by lower crude all-cause medical costs PPPM in the dutasteride + $\mathrm{AB}$ cohort relative to the finasteride $+\mathrm{AB}$ cohort ( $\$ 471$ vs. $\$ 575$, $P=0.0003$.

The crude results just presented may be a result of differences in baseline characteristics between the 2 cohorts. Therefore, adjusted results from IPT weighted regression models for the main analysis and sensitivity analysis study samples are presented in Table 3. Based on adjusted estimates from the IPT weighted Cox proportional hazards model, no statistically significant associations between dutasteride (compared with finasteride) and AUR (hazard ratio $[\mathrm{HR}]=0.845$, 95\% confidence interval $[\mathrm{CI}]=0.660-1.070, \quad P=0.1643)$, 
Comparing Clinical and Economic Outcomes Associated with Early Initiation of Combination Therapy of an Alpha Blocker and Dutasteride or Finasteride in Men with Benign Prostatic Hyperplasia in the United States

\section{FIGURE 2 Identification of Study Population}

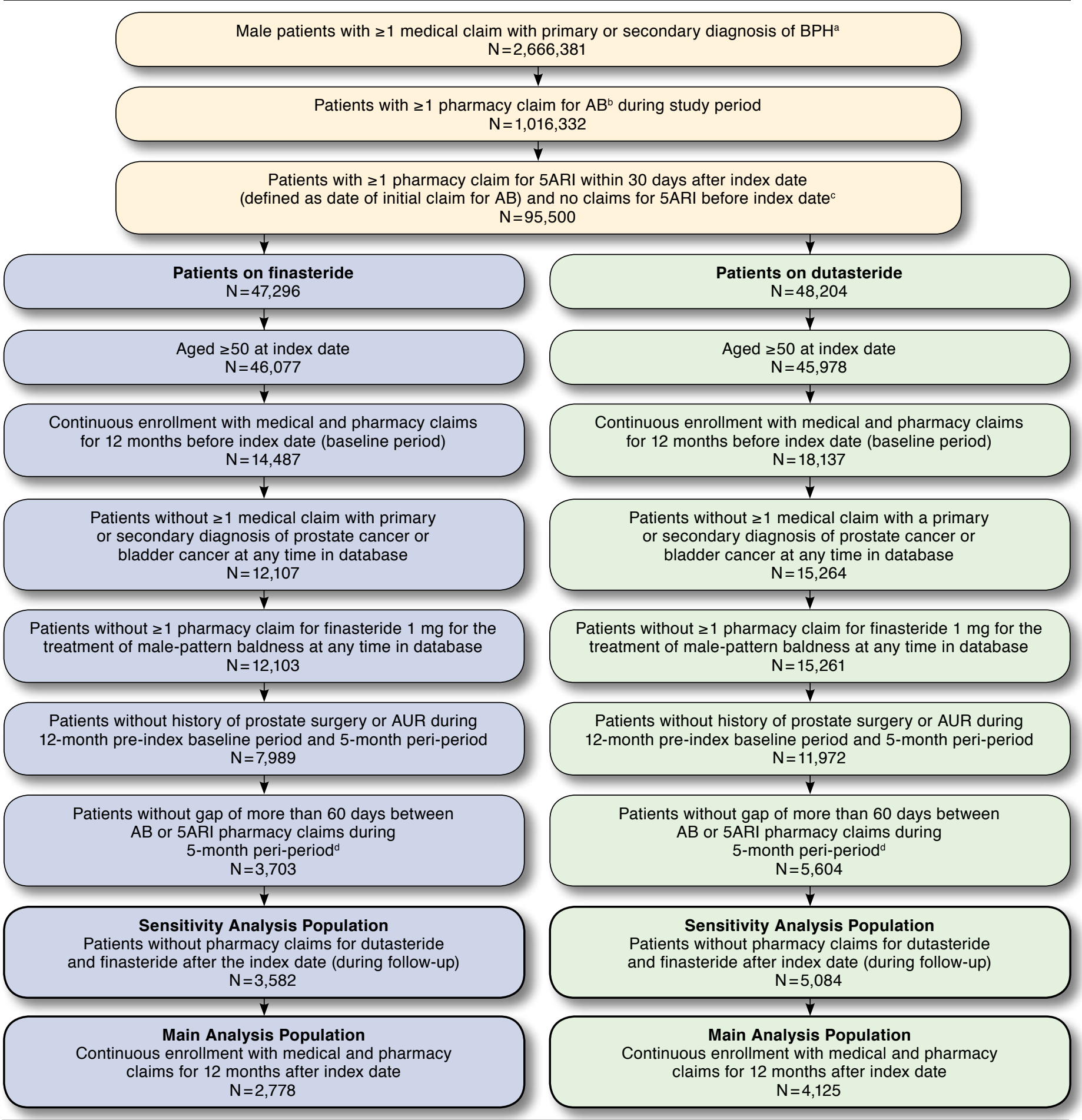

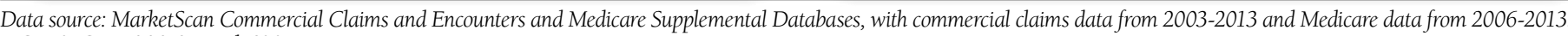
ICD-9-CM $=222.2 x$ and $600 . x x$

${ }^{b} A B$ agents include alfuzosin, doxazosin, tamsulosin, and terazosin. Some patients were also on Jalyn, a combination dutasteride + tamsulosin treatment.

cSome patients on combination AB+5ARI therapy (i.e., Jalyn) had this treatment as their index AB treatment.

dExcludes patients with a drug claim that has days supply $\leq 0$. Days supply is added to the previous claim.

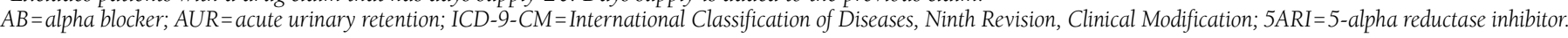


Dutasteride

$\mathrm{n}=4,125$

$64.8 \pm 9.1[63.0]$

Age, mean \pm SD [median]

Geographic region

\begin{tabular}{l|r}
\hline North central & 1,252 \\
\hline Northeast & 508 \\
\hline South & 1,722 \\
\hline West & 627 \\
\hline Unknown & 16
\end{tabular}

Insurance type

Comprehensive

$\mathrm{HMO}$

POS

$\mathrm{PPO}$

Other

Unknown

Payer type

Commercial

Medicare

Generic finasteride available on index date

Year of index date

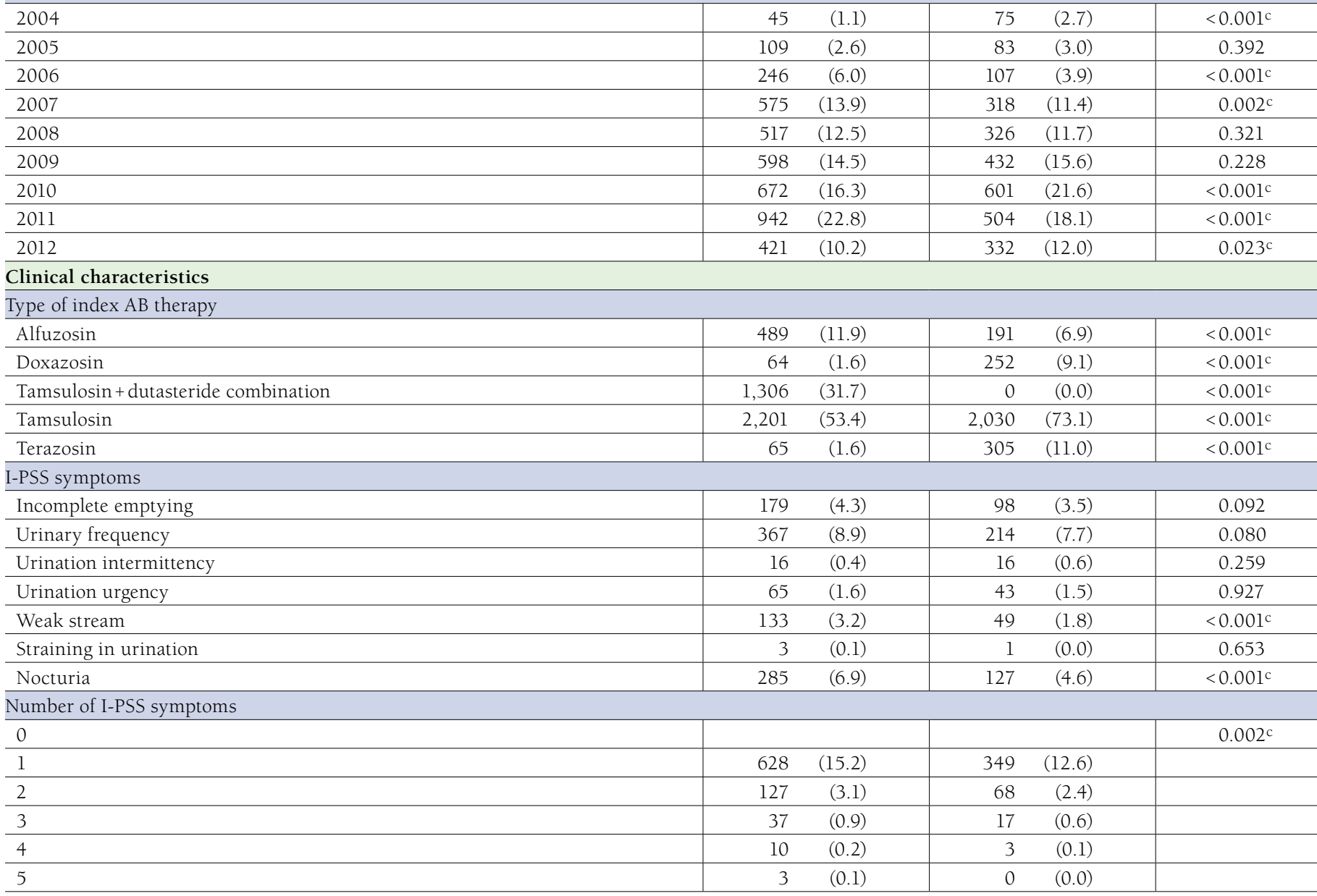


TABLE 1 Baseline Demographic, Clinical, and Economic Characteristics of Study Population (continued)

\begin{tabular}{|c|c|c|c|}
\hline Patient Characteristics at Baseline ${ }^{a}$ & $\begin{array}{c}\text { Dutasteride } \\
\mathrm{n}=4,125\end{array}$ & $\begin{array}{c}\text { Finasteride } \\
\mathbf{n}=2,778\end{array}$ & $P$ Value ${ }^{\mathrm{b}}$ \\
\hline Time from first pre-index symptom to index date (days), mean \pm SD [median] & $76.9 \pm 95.6[35.0]$ & $82.0 \pm 98.3[36.0]$ & 0.696 \\
\hline \multicolumn{4}{|l|}{ BPH stage } \\
\hline 1.1 & $(44.8)$ & $(35.2)$ & $<0.001^{c}$ \\
\hline 1.2 & $(5.1)$ & $(5.1)$ & 0.995 \\
\hline 2.1 & $(1.4)$ & $(0.9)$ & 0.096 \\
\hline 2.2 & $(0.3)$ & $(0.6)$ & 0.143 \\
\hline 3.1 & $(1.0)$ & $(1.2)$ & 0.597 \\
\hline 3.2 & $(0.4)$ & $(0.7)$ & 0.089 \\
\hline 3.3 & $(0.0)$ & $(0.1)$ & 0.569 \\
\hline No BPH diagnosis & $(47.0)$ & $(56.2)$ & $<0.001^{\mathrm{c}}$ \\
\hline Quan-Charlson Comorbidity Index, mean \pm SD [median] & $0.8 \pm 1.3$ & $1.0 \pm 1.5$ & $<0.001^{\mathrm{c}}$ \\
\hline \multicolumn{4}{|l|}{ Presence of specific conditions } \\
\hline Hematuria & $(12.2)$ & $(13.8)$ & 0.055 \\
\hline Bladder dysfunction & $(0.9)$ & $(1.0)$ & 0.565 \\
\hline Urinary incontinence & $(1.9)$ & $(2.6)$ & $0.040^{c}$ \\
\hline Bladder stones & $(5.1)$ & $(5.5)$ & 0.459 \\
\hline Number of visits to urologist, mean \pm SD [median] & $10.7 \pm 28.5$ & $7.9 \pm 30.2$ & $<0.001^{\mathrm{c}}$ \\
\hline Time from AB (index date) to date of 5ARI, (days), mean \pm SD [median] & $2.4 \pm 6.8$ & $3.2 \pm 7.6$ & $<0.001^{\mathrm{c}}$ \\
\hline \multicolumn{4}{|l|}{ Health care cost (per month) } \\
\hline \multicolumn{4}{|l|}{ All-cause, mean \pm SD [median] } \\
\hline Total costs & $1,026.6 \pm 2,148.9[475.9]$ & $1,220.0 \pm 2,633.4[488.7]$ & 0.335 \\
\hline Medical costs & $773.2 \pm 2,045.6[254.1]$ & $1,014.7 \pm 2,559.4[286.3]$ & $<0.001^{\mathrm{c}}$ \\
\hline Pharmacy costs & $253.3 \pm 429.4[143.7]$ & $205.3 \pm 337.0[104.9]$ & $<0.001^{\mathrm{c}}$ \\
\hline \multicolumn{4}{|l|}{ BPH-related, mean \pm SD [median] } \\
\hline Total costs & $44.7 \pm 472.9 \quad[4.0]$ & $67.8 \pm 445.0 \quad[0.0]$ & $<0.001^{\mathrm{c}}$ \\
\hline Medical costs & $44.7 \pm 472.9 \quad[4.0]$ & $67.8 \pm 445.0 \quad[0.0]$ & $<0.001^{\mathrm{c}}$ \\
\hline \multicolumn{4}{|c|}{$\begin{array}{l}\text { a All findings presented as } n(\%), \text { unless otherwise noted. } \\
\text { bChi-square test was used for categorical variables, and Fisher's exact test was used for categorical variables with cell sizes }<5 \text { in the study sample. Wilcoxon test was used } \\
\text { for continuous variables in the study sample. } \\
\text { cP value }<0.05 \text {. }\end{array}$} \\
\hline
\end{tabular}

prostate-related surgery $(\mathrm{HR}=0.806,95 \% \mathrm{CI}=0.568-1.171$, $P=0.2525)$, and clinical progression $(H R=0.834,95 \%$ $\mathrm{CI}=0.663-1.043, P=0.1122$ ) were observed. Similar results were observed for clinical outcomes in the sensitivity analysis. On average, the adjusted mean difference in all-cause related pharmacy costs PPPM between the dutasteride and finasteride groups indicated significantly higher costs associated with dutasteride treatment (adjusted cost difference PPPM $=\$ 79$, $95 \% \mathrm{CI}=\$ 45-\$ 105, P=0.0040$ ). The adjusted monthly difference in medical costs was not significantly different between the dutasteride and finasteride cohorts $(-\$ 44,95 \% \mathrm{CI}=-\$ 110$ $\$ 22, P=0.2004)$, although results may suggest a partial offset of higher pharmacy costs in dutasteride users. In contrast to results from the main analyses, monthly all-cause medical costs in dutasteride users were statistically significantly $\$ 61$ less $(95 \% \mathrm{CI}=-\$ 121$ to $-\$ 3, P=0.0321)$ than in finasteride users in the sensitivity analysis, but a statistically significant difference in total all-cause health care costs between the 2 cohorts was not observed in the main or sensitivity analyses.
There were no statistically significant differences in monthly health care resource utilization rates between the dutasteride and finasteride treatment cohorts except for all-cause outpatient visits (incidence rate ratio $[\mathrm{IRR}]=1.079,95 \% \mathrm{CI}=1.006$ $1.154, P=0.0401)$ and BPH-related emergency room visits (IRR $=0.448,95 \% \mathrm{CI}=0.194-0.960, P=0.0441$ ). This conclusion is based on the fact that most IRRs for the association between dutasteride and health care resource utilization were close to 1.0 with wide $95 \%$ CIs that crossed the null.

\section{Discussion}

The main objectives of this study were to compare clinical and economic outcomes related to $\mathrm{BPH}$ in patients treated with early combination dutasteride $+A B$ and finasteride $+A B$. Adjusted results indicate that that the risk of AUR, prostate-related surgery, or clinical progression were not statistically significantly different between patients treated with early dutasteride $+A B$ compared with those treated with early finasteride $+A B$. Total all-cause health care costs were not significantly different 
TABLE 2 Crude Comparisons of Clinical Outcomes, Health Care Resource Utilization, and Health Care Costs During Observation Period

\begin{tabular}{|c|c|c|c|}
\hline \multirow[b]{2}{*}{ Outcomes } & \multicolumn{3}{|c|}{ Crude Comparison } \\
\hline & $\begin{array}{c}\text { Dutasteride } \\
\mathrm{n}=4,125 \\
\mathrm{n}(\%)\end{array}$ & $\begin{array}{c}\text { Finasteride } \\
\mathbf{n}=2,778 \\
\mathbf{n}(\%)\end{array}$ & \multirow[t]{2}{*}{$P$ Value ${ }^{c}$} \\
\hline \multicolumn{3}{|l|}{ Clinical outcomes $^{a}$} & \\
\hline AUR & $(3.3)$ & $129 \quad(4.6)$ & $0.0061^{\mathrm{d}}$ \\
\hline Prostate-related surgery & $(2.1)$ & $(2.6)$ & 0.1223 \\
\hline Clinical progression & $(4.8)$ & $(6.4)$ & $0.0032^{\mathrm{d}}$ \\
\hline \multicolumn{4}{|l|}{ Incidence of I-PSS symptoms } \\
\hline Incomplete emptying & $(4.7)$ & $(5.1)$ & 0.4799 \\
\hline Urinary frequency & $222 \quad(5.4)$ & $(6.1)$ & 0.1941 \\
\hline Urination intermittency & $(0.3)$ & $(0.4)$ & 0.8867 \\
\hline Urination urgency & $(1.2)$ & $(1.9)$ & $0.0084^{d}$ \\
\hline Weak stream & $(2.5)$ & $(2.3)$ & 0.6533 \\
\hline Straining in urination & $(0.0)$ & $(0.1)$ & 1.0000 \\
\hline Nocturia & $234 \quad(5.7)$ & $160 \quad(5.8)$ & 0.8788 \\
\hline Health care costs (per month)b & Mean \pm SD [Median] & Mean \pm SD [Median] & \\
\hline \multicolumn{4}{|l|}{ All-cause } \\
\hline Total costs & $911.93 \pm 1,407.41 \quad[524.02]$ & $929.36 \pm 1,736.66 \quad[456.18]$ & $<0.0001^{\mathrm{d}}$ \\
\hline Medical costs & $470.84 \pm 1,250.70 \quad[121.63]$ & $575.33 \pm 1,574.98 \quad[135.30]$ & $0.0003^{\mathrm{d}}$ \\
\hline Pharmacy costs & $441.09 \pm 486.48 \quad[326.21]$ & $354.03 \pm 549.79 \quad[239.01]$ & $<0.0001^{\mathrm{d}}$ \\
\hline \multicolumn{4}{|l|}{ BPH-related } \\
\hline Total costs & $208.79 \pm 429.17 \quad[162.71]$ & $141.72 \pm 243.26 \quad[91.65]$ & $<0.0001^{\mathrm{d}}$ \\
\hline Medical costs & $55.72 \pm 425.75 \quad[2.40]$ & $49.12 \pm 237.27 \quad[2.91]$ & 0.3299 \\
\hline Pharmacy costs & $153.06 \pm 51.10 \quad[149.73]$ & $92.60 \pm 58.74 \quad[73.75]$ & $<0.0001^{\mathrm{d}}$ \\
\hline \multicolumn{4}{|c|}{ Health care resource utilization (per month) } \\
\hline \multicolumn{4}{|c|}{ All-cause } \\
\hline Inpatient admission & $0.007 \pm 0.025$ & $0.011 \pm 0.033 \quad[0.000]$ & $<0.0001^{\mathrm{d}}$ \\
\hline Length of stay of inpatient visit & $0.038 \pm 0.166 \quad[0.000]$ & $0.064 \pm 0.251 \quad[0.000]$ & $<0.0001^{d}$ \\
\hline Outpatient visit & $0.733 \pm 0.875 \quad[0.495]$ & $0.790 \pm 0.840 \quad[0.544]$ & $0.0010^{\mathrm{d}}$ \\
\hline Emergency room visit & $0.012 \pm 0.044 \quad[0.000]$ & $0.018 \pm 0.052 \quad[0.000]$ & $<0.0001^{\mathrm{d}}$ \\
\hline Other medical ancillary services & $0.074 \pm 0.241$ & $0.111 \pm 0.469 \quad[0.000]$ & $0.0072^{\mathrm{d}}$ \\
\hline \multicolumn{4}{|l|}{ BPH-related } \\
\hline Inpatient admission & $0.001 \pm 0.011 \quad[0.000]$ & $0.001 \pm 0.010 \quad[0.000]$ & 0.5871 \\
\hline Length of stay of inpatient visit & $0.006 \pm 0.053 \quad[0.000]$ & $0.006 \pm 0.058 \quad[0.000]$ & 0.5843 \\
\hline Outpatient visit & $0.067 \pm 0.096 \quad[0.032]$ & $0.065 \pm 0.095 \quad[0.034]$ & 0.7013 \\
\hline Emergency room visit & $0.000 \pm 0.005$ & $0.001 \pm 0.008 \quad[0.000]$ & $0.0027^{\mathrm{d}}$ \\
\hline Other medical ancillary services & $\begin{array}{ll}0.002 \pm 0.039 & {[0.000]} \\
\end{array}$ & $\begin{array}{ll}0.002 \pm 0.025 & {[0.000]} \\
\end{array}$ & 0.0521 \\
\hline \multicolumn{4}{|c|}{$\begin{array}{l}\text { a Outcomes assessed after 5-month peri-period. } \\
{ }^{b} \text { Medical costs were evaluated after the 5-month peri-period, while pharmacy costs were assessed over the entire observation period followin } \\
\text { cChi-square test was used for categorical variables. Fisher's exact test was used for categorical variables with cell sizes }<5 \text {. Wilcoxon test was } \\
\text { dP value }<0.05 \text {. } \\
\text { AUR =acute urinary retention; BPH = benign prostatic hyperplasia; I-PSS = International Prostate Symptom Score; SD = standard deviation. }\end{array}$} \\
\hline
\end{tabular}

between the 2 cohorts either, although total all-cause medical costs were significantly lower in patients treated with dutasteride in the sensitivity analysis. Indeed, the sensitivity analysis demonstrated similar results for a larger group of patients who were not required to have continuous enrollment with medical or pharmacy benefits for at least 12 months.

The goal of effectively managing BPH is to provide patients with symptom relief, slow the growth of the prostate, prevent complications, and improve overall quality of life. ${ }^{1,13,34}$
Evidence-based treatment guidelines recommend $\mathrm{ABs}$ and 5ARIs, either as monotherapy or as combination therapy, for the treatment of BPH symptoms before or instead of surgery. ${ }^{13}$ However, there is no consensus regarding differences between the two 5ARIs currently approved for use in the United States. While statistically significant differences in clinical outcomes and total all-cause health care costs between the dutasteride and finasteride cohorts were not found in this study, it is hypothesized that the dual inhibition of both isoforms 
TABLE 3 Adjusted (Weighted) Regression Results for Main Analysis and Sensitivity Analysis Study Samples

\begin{tabular}{|c|c|c|c|c|c|c|}
\hline \multirow[b]{2}{*}{ Outcomes } & \multirow{2}{*}{\multicolumn{3}{|c|}{$\begin{array}{l}\text { Adjusted (Weighted) Estimates in Main Analysis } \\
\qquad \mathrm{n}=6,903 \\
\text { Dutasteride vs. Finasteride }\end{array}$}} & \multirow{2}{*}{\multicolumn{3}{|c|}{\begin{tabular}{|c|}
$\begin{array}{c}\text { Adjusted (Weighted) Estimates in Sensitivity Analysis } \\
\mathrm{n}=8,666\end{array}$ \\
Dutasteride vs. Finasteride \\
\end{tabular}}} \\
\hline & & & & & & \\
\hline \multirow[b]{2}{*}{ Clinical outcomes $^{a}$} & \multirow[b]{2}{*}{ Hazard Ratio } & \multicolumn{2}{|c|}{ Bootstrap-Based ${ }^{c}$} & \multirow[b]{2}{*}{ Hazard Ratio } & \multicolumn{2}{|c|}{ Bootstrap-Basedc } \\
\hline & & $95 \% \mathrm{CI}$ & $P$ Value & & $95 \% \mathrm{CI}$ & $P$ Value \\
\hline Acute urinary retention & 0.845 & $(0.660-1.070)$ & 0.1643 & 0.792 & $(0.614-1.022)$ & 0.0641 \\
\hline Prostate-related surgery & 0.806 & $(0.568-1.171)$ & 0.2525 & 0.816 & $(0.595-1.148)$ & 0.2084 \\
\hline Clinical progression & 0.834 & $(0.663-1.043)$ & 0.1122 & 0.824 & $(0.663-1.022)$ & 0.0721 \\
\hline \multirow{2}{*}{$\begin{array}{l}\text { Health care costsb } \\
\text { (per month) }\end{array}$} & \multirow{2}{*}{$\begin{array}{c}\text { Mean } \\
\text { Difference }\end{array}$} & \multicolumn{2}{|c|}{ Bootstrap-Based ${ }^{c}$} & \multirow{2}{*}{$\begin{array}{c}\text { Mean } \\
\text { Difference }\end{array}$} & \multicolumn{2}{|c|}{ Bootstrap-Based ${ }^{c}$} \\
\hline & & $95 \% \mathrm{CI}$ & $P$ Value & & $95 \%$ CI & $P$ Value \\
\hline \multicolumn{7}{|l|}{ All-cause } \\
\hline Total costs & 35.069 & $(-47.069-109.052)$ & 0.3447 & 18.682 & $(-49.206-88.331)$ & 0.5691 \\
\hline Medical costs & -43.867 & $(-109.648-22.045)$ & 0.2004 & -60.666 & $(-120.756$ to -2.515$)$ & $0.0321^{\mathrm{d}}$ \\
\hline Pharmacy costs & 78.936 & $(45.458-104.793)$ & $0.0040^{\mathrm{d}}$ & 79.348 & (55.999-101.959) & $<0.0001^{\mathrm{d}}$ \\
\hline \multicolumn{7}{|l|}{ BPH-related } \\
\hline Total costs & 56.960 & $(39.903-76.684)$ & $<0.0001^{\mathrm{d}}$ & 57.996 & $(44.893-73.139)$ & $<0.0001^{\mathrm{d}}$ \\
\hline Medical costs & 6.563 & $(-10.449-25.875)$ & 0.4289 & 5.549 & $(-6.784-20.038)$ & 0.4208 \\
\hline Pharmacy costs & 50.397 & $(48.083-52.630)$ & $<0.0001^{\mathrm{d}}$ & 52.447 & $(50.115-54.534)$ & $<0.0001^{\mathrm{d}}$ \\
\hline \multirow{2}{*}{$\begin{array}{l}\text { Health care resource } \\
\text { utilizatione (per month) }\end{array}$} & \multirow{2}{*}{$\begin{array}{l}\text { Incidence } \\
\text { Rate Ratio }\end{array}$} & \multicolumn{2}{|c|}{ Bootstrap-Basedc } & \multirow{2}{*}{$\begin{array}{l}\text { Incidence } \\
\text { Rate Ratio }\end{array}$} & \multicolumn{2}{|l|}{ Bootstrap-Based c } \\
\hline & & $95 \%$ CI & $P$ Value & & $95 \% \mathrm{CI}$ & $P$ Value \\
\hline \multicolumn{7}{|l|}{ All-cause } \\
\hline Inpatient admission & 0.976 & $(0.806-1.165)$ & 0.8297 & 1.003 & $(0.829-1.202)$ & 0.9579 \\
\hline Length of stay of inpatient visit & 0.871 & $(0.693-1.097)$ & 0.2325 & 0.973 & $(0.748-1.219)$ & 0.8537 \\
\hline Outpatient visit & 1.079 & $(1.006-1.154)$ & $0.0401^{\mathrm{d}}$ & 1.075 & $(0.988-1.143)$ & 0.0922 \\
\hline Emergency room visit & 0.874 & $(0.738-1.052)$ & 0.1884 & 0.866 & $(0.723-1.029)$ & 0.0802 \\
\hline Other medical ancillary services & 0.973 & $(0.773-1.227)$ & 0.8016 & 0.981 & $(0.784-1.202)$ & 0.7856 \\
\hline \multicolumn{7}{|l|}{ BPH-related } \\
\hline Inpatient admission & 1.348 & $(0.778-2.191)$ & 0.2244 & 1.338 & $(0.874-2.196)$ & 0.1683 \\
\hline Length of stay of inpatient visit & 1.224 & $(0.774-2.050)$ & 0.3928 & 1.169 & $(0.745-1.937)$ & 0.4609 \\
\hline Outpatient visit & 1.060 & $(0.956-1.156)$ & 0.2645 & 1.039 & $(0.936-1.126)$ & 0.3727 \\
\hline Emergency room visit & 0.448 & $(0.194-0.960)$ & $0.0441^{\mathrm{d}}$ & 0.502 & $(0.253-0.981)$ & $0.0441^{\mathrm{d}}$ \\
\hline Other medical ancillary services & 1.031 & $(0.382-2.704)$ & 0.9659 & 0.819 & $(0.341-1.687)$ & 0.5491 \\
\hline \multicolumn{7}{|c|}{$\begin{array}{l}\text { aClinical outcomes modeled using normalized unstabilized IPT weighted Cox proportional hazards models. Outcomes assessed after 5-month peri-period. } \\
{ }^{b} \text { Cost outcomes modeled using normalized unstabilized IPT weighted linear regression models. Medical costs were evaluated after 5-month peri-period, while pharmacy } \\
\text { costs were assessed over the entire observation period following the index date. } \\
{ }^{c} \text { Nonparametric bootstrap procedure used to obtain } 95 \% \text { CIs and P values based on } 499 \text { resamples of the analytical dataset. } \\
\text { dP value }<0.05 \text {. } \\
{ }^{e} \text { Health care resource utilization outcomes modeled using normalized unstabilized IPT weighted Poisson regression models. Outcomes assessed after 5-month peri-period. } \\
B P H=\text { benign prostatic hyperplasia; CI= confidence interval; IPT = inverse probability of treatment. }\end{array}$} \\
\hline
\end{tabular}

of $5 a$-reductase and longer half-life associated with dutasteride may confer improved clinical outcomes, ${ }^{35,36}$ resulting in reduced health care resource utilization and costs associated with treating BPH. In a previous study, Issa et al. (2007) used administrative claims data to assess differences between dutasteride and finasteride in a managed care population aged older than 50 years and found that AUR and BPH-related surgery rates were lower in the dutasteride group compared with the finasteride group. ${ }^{37}$ A study by Fenter et al. (2008) also reported lower rates of AUR and prostate-related surgery among elderly patients aged 65 years or older treated with dutasteride compared with those treated with finasteride ${ }^{38} \mathrm{~A}$ third retrospective study conducted among Italian men found that dutasteride was associated with a significantly lower risk of hospitalization for BPH-related surgery than finasteride. ${ }^{39}$ Previous studies have also shown that medical costs are lower in patients treated with dutasteride compared with those treated with finasteride. ${ }^{40,41}$ To date, the Enlarged Prostate Comparator Study (EPICS) is the only randomized clinical trial comparing dutasteride and finasteride..$^{42}$ Although the investigators did not find significant differences in efficacy outcomes between the 2 treatment groups, the 1-year duration of the study may not have been sufficient to detect such differences, considering the chronic and progressive nature of BPH. Results 
from this study were similarly inconclusive in definitively differentiating between dutasteride and finasteride with respect to outcomes, which may also be a result of the shorter duration of follow-up among patients in the study.

A number of study design considerations were made in order to strengthen the internal validity of the present study. For instance, patients with a history of AUR or prostate surgery during the baseline period or peri-period were excluded, since these patients may have had more severe disease, which may have contributed to confounding by indication (about 53\% of eligible patients were removed at this step of the sample selection in both treatment cohorts). ${ }^{23}$ Thus, while the results of this study may not be generalizable to all BPH patients, they apply to a population of patients with earlier stages of disease. In addition, patients were required to be continuously treated with combination $5 \mathrm{ARI}+\mathrm{AB}$ therapy during follow-up in order to ensure that the outcomes assessed were, in fact, attributable to the treatments the patients received. If patients were allowed to be nonadherent to their treatments, or were not continuously treated, then it may not necessarily be appropriate to attribute their outcomes to the treatment received, since the effect of $5 \mathrm{ARI}+\mathrm{AB}$ combination therapy does not continue for a long period of time after the patient stops treatment. In fact, previous studies have shown that discontinuation of 5ARI results in prostrate regrowth and exacerbation of lower urinary tract symptoms. ${ }^{43,44}$ However, the shorter duration of patient follow-up as a result of this may have prevented the observation of significant differences in clinical outcomes and medical costs between the 2 cohorts, as mentioned previously. In addition, differences in unmeasured baseline characteristics may remain, and confounding by indication may contribute to the nonsignificant results for clinical outcomes.

\section{Limitations}

Several limitations should be considered when interpreting findings from this study. First, the selection of patients with $\mathrm{BPH}$ and the identification of outcomes and certain covariates were based on ICD-9-CM diagnosis codes. As such, coding inaccuracies may have led to misclassification bias and misidentification of patients with BPH. Second, it was assumed that a patient with a claim for 5ARI and AB therapy was using these therapies as directed by a physician. However, patients may not have adhered to the prescribed treatment regimen. While patients were censored when a gap of 60 days between $\mathrm{AB}$ or 5ARI pharmacy claims occurred in order to account for nonadherence to the prescribed therapies, the treatment variable may have been affected by some degree of inaccuracy. This issue may be exacerbated, since treatment received during inpatient hospital stays was not captured in the dataset. Third, although the study aimed to control for confounding by indication by adjusting for baseline covariates that were thought to be indicators of underlying disease severity, such as I-PSS symptoms, via IPT weighting, some residual confounding may have remained and could have contributed to the nonsignificance of results observed. Fourth, the generalizability of the results is limited to a population covered by employersponsored health care or supplemental Medicare plans and patients in earlier phases of disease. Thus, the results may not be generalized to the entire U.S. population or to individuals covered by other federal insurance programs (e.g., Medicare fee for service, Medicaid, and Veterans Affairs) and should be applied to individual care settings cautiously. Finally, as is often the case with retrospective analyses of administrative claims data, missing information may have resulted in selection bias, confounding, and measurement error.

\section{Conclusions}

Statistically significant differences in clinical and economic outcomes among patients treated with early dutasteride $+\mathrm{AB}$ combination therapy versus finasteride $+A B$ therapy were not found.

\section{Authors}

MARAL DERSARKISSIAN, PhD, Analysis Group, Los Angeles, California; YONGLING XIAO, PhD, and PATRICK LEFEBVRE, MA, Groupe d'analyse, Ltée, Montréal, Québec, Canada; and MEI SHENG DUH, MPH, ScD, Analysis Group, Boston, Massachusetts. ANDRINE R. SWENSEN, MS, PhD, and CHRISTOPHER F. BELL, MS, GlaxoSmithKline, Research Triangle Park, North Carolina.

AUTHOR CORRESPONDENCE: Christopher F. Bell, MS, Therapeutic Area Director, CVMHU, USMA Health Outcomes, US Medical Affairs, GlaxoSmithKline, 5 Moore Dr., Research Triangle Park, NC 27709. Tel.: 919.483.8058; E-mail: Christopher.f.bell@gsk.com.

\section{DISCLOSURES}

Funding for this study was provided by GlaxoSmithKline (HO-14-15325 and AVO110072). Bell and Swensen are employees of GlaxoSmithKline. DerSarkissian, Xiao, Duh, and Lefebvre are employed by Analysis Group, a consulting company that received research grants from GlaxoSmithKline to conduct this study.

Study concept and design were contributed by Bell, Swensen, Lefebvre and Duh. Bell and Duh acquired the data. DerSarkissian and Xiao performed the statistical analysis and interpreted the data along with Lefebvre, Duh, and Bell. DerSarkissian and Bell drafted the manuscript. All authors contributed equally to critically revising the manuscript and providing final approval of the submitted manuscript.

\section{REFERENCES}

1. Logan YT, Belgeri MT. Monotherapy versus combination drug therapy for the treatment of benign prostatic hyperplasia. Am J Geriatr Pharmacother. 2005;3(2):103-14.

2. Emberton M, Cornel EB, Bassi PF, et al. Benign prostatic hyperplasia as a progressive disease: a guide to the risk factors and options for medical management. Int J Clin Pract. 2008;62(7):1076-86.

3. Foster CS. Pathology of benign prostatic hyperplasia. Prostate Suppl. 2000;9:4-14 


\section{Comparing Clinical and Economic Outcomes Associated with Early Initiation of Combination Therapy of an Alpha Blocker and Dutasteride or Finasteride in Men with Benign Prostatic Hyperplasia in the United States}

4. Cohen SA, Parsons JK. Combination pharmacological therapies for the management of benign prostatic hyperplasia. Drugs Aging. 2012;29(4):275-84. 5. Auffenberg GB, Helfand BT, McVary KT. Established medical therapy for benign prostatic hyperplasia. Urol Clin North Am. 2009;36(4):443-59.

6. Fong YK, Milani S, Djavan B. Natural history and clinical predictors of clinical progression in benign prostatic hyperplasia. Cur Opin Urol. 2005;15(1):35-38

7. Roehrborn CG, Barkin J, Siami P, et al. Clinical outcomes after combined therapy with dutasteride plus tamsulosin or either monotherapy in men with benign prostatic hyperplasia (BPH) by baseline characteristics: 4-year results from the randomized, double-blind Combination of Avodart and Tamsulo. BJU Int. 2011;107(6):946-54.

8. Emberton M, Andriole GL, de la Rosette J, et al. Benign prostatic hyperplasia: a progressive disease of aging men. Urology. 2003;61(2):267-73.

9. Emberton M, Fitzpatrick JM, Garcia-Losa M, et al. Progression of benign prostatic hyperplasia: systematic review of the placebo arms of clinical trials BJU Int. 2008;102(8):981-86.

10. Jacobsen SJ, Girman CJ, Lieber MM. Natural history of benign prostatic hyperplasia. Urology. 2001;58(6 Suppl 1):5-16.

11. Wei JT, Calhoun E, Jacobsen SJ. Urologic diseases in America project: benign prostatic hyperplasia. J Urol. 2005;173(4):1256-61.

12. Naslund M, Eaddy MT, Hogue SL, et al. Impact of delaying 5-alpha reductase inhibitor therapy in men on alpha-blocker therapy to treat BPH: assessment of acute urinary retention and prostate-related surgery. Curr Med Res Opin. 2009;25(11):2663-69.

13. AUA Practice Guidelines Committee. AUA guideline on management of benign prostatic hyperplasia (2003). Chapter 1: Diagnosis and treatment recommendations. J Urol. 2003;170(2 Pt 1):530-47.

14. McConnell JD, Roehrborn CG, Bautista OM, et al. The long-term effect of doxazosin, finasteride, and combination therapy on the clinical progression of benign prostatic hyperplasia. N Engl J Med. 2003;349(25):2387-98. 15. McConnell JD, Bruskewitz R, Walsh P, et al. The effect of finasteride on the risk of acute urinary retention and the need for surgical treatment among men with benign prostatic hyperplasia. Finasteride Long-Term Efficacy and Safety Study Group. N Engl J Med. 1998;338(9):557-63. 16. Emberton M, Zinner N, Michel MC, et al. Managing the progression of lower urinary tract symptoms/benign prostatic hyperplasia: therapeutic options for the man at risk. BJU Int. 2007;100(2):249-53.

17. Shapiro E, Hartanto V, Lepor H. The response to alpha blockade in benign prostatic hyperplasia is related to the percent area density of prostate smooth muscle. Prostate. 1992;21(4):297-307.

18. Roehrborn CG, Siami P, Barkin J, et al. The effects of combination therapy with dutasteride and tamsulosin on clinical outcomes in men with symptomatic benign prostatic hyperplasia: 4-year results from the CombAT study. Eur Urol. 2010;57(1):123-31.

19. Kruep EJ, Phillips E, Hogue S, et al. Early symptom improvement and discontinuation of 5-a-reductase inhibitor (5ARI) therapy in patients with benign prostatic hyperplasia (BPH). Ann Pharmacother. 2014;48(3):343-48. 20. Roehrborn CG, Siami P, Barkin J, et al. The effects of dutasteride, tamsulosin and combination therapy on lower urinary tract symptoms in men with benign prostatic hyperplasia and prostatic enlargement: 2 -year results from the CombAT study. J Urol. 2008;179(2):616-21.

21. Greco KA, McVary KT. The role of combination medical therapy in benign prostatic hyperplasia. Int J Impot Res. 2008;20(Suppl 3):S33-43.

22. Roehrborn CG, Barkin J, Tubaro A, et al. Influence of baseline variables on changes in International Prostate Symptom Score after combined therapy with dutasteride plus tamsulosin or either monotherapy in patients with benign prostatic hyperplasia and lower urinary tract symptoms: 4-year results. BJU Int. 2014;113(4):623-35.

23. Kruep EJ, Hogue SL, Eaddy MT, et al. Clinical and economic impact of early versus delayed 5-alpha reductase inhibitor therapy in men taking alpha blockers for symptomatic benign prostatic hyperplasia. P T. 2011;36(8):493-507.

24. Morlock R, Goodwin B, Gomez Rey G, et al. Clinical progression, acute urinary retention, prostate-related surgeries, and costs in patients with benign prostatic hyperplasia taking early versus delayed combination $5 \alpha$-reductase inhibitor therapy and $\alpha$-blocker therapy: a retrospective analysis. Clin Ther. 2013;35(5):624-33.
25. Cindolo L, Pirozzi L, Fanizza C, et al. Drug adherence and clinical outcomes for patients under pharmacological therapy for lower urinary tract symptoms related to benign prostatic hyperplasia: population-based cohort study. Eur Urol. 2015;68(3):418-25.

26. Roehrborn CG, Perez IO, Roos EP, et al. Efficacy and safety of a fixeddose combination of dutasteride and tamsulosin treatment (Duodart) compared with watchful waiting with initiation of tamsulosin therapy if symptoms do not improve, both provided with lifestyle advice, in the management of treatment-naive men with moderately symptomatic benign prostatic hyperplasia: 2-year CONDUCT study results. BJU Int. 2015;116(3):450-59. 27. Filson CP, Wei JT, Hollingsworth JM. Trends in medical management of men with lower urinary tract symptoms suggestive of benign prostatic hyperplasia. Urology. 2013;82(6):1386-92.

28. Avodart (dutasteride) soft gel capsules. GlaxoSmithKline. Revised September 2014. Available at: https://www.gsksource.com/pharma/content/dam/GlaxoSmithKline/US/en/Prescribing_Information/Avodart/pdf/ AVODART-PI-PIL.PDF. Accessed September 1, 2016.

29. Proscar (finasteride) tablets. Merck. \& Co. October 2010. Available at: http://www.accessdata.fda.gov/drugsatfda_docs/label/2010/020180s037lbl. pdf. Accessed September 1, 2016.

30. Charlson ME, Pompei P, Ales KL, et al. A new method of classifying prognostic comorbidity in longitudinal studies: development and validation. J Chronic Dis. 1987;40(5):373-83.

31. Quan H, Sundararajan V, Halfon P, et al. Coding algorithms for defining comorbidities in ICD-9-CM and ICD-10 administrative data. Med Care. 2005;43(11):1130-39

32. Gonnella J, Louis D, Gozum M, et al. Disease Staging: Clinical and Coded Criteria. 5th ed. Ann Arbor, MI: Thomson Medstat; 2003.

33. Robins JM, Hernán MA, Brumback B. Marginal structural models and causal inference in epidemiology. Epidemiology. 2000;11(5):550-60.

34. Lowe FC. Goals for benign prostatic hyperplasia therapy. Urology. 2002;59(2):1-2.

35. Naslund M, Regan TS, Ong C, et al. 5-alpha reductase inhibitors in men with an enlarged prostate: an evaluation of outcomes and therapeutic alternatives. Am J Manag Care. 2008;14(5 Suppl 2):S148-53.

36. Marihart S, Harik M, Djavan B. Dutasteride: a review of current data on a novel dual inhibitor of 5alpha reductase. Rev Urol. 2005;7(4):203-10.

37. Issa MM, Runken MC, Grogg AL, et al. A large retrospective analysis of acute urinary retention and prostate-related surgery in BPH patients treated with 5-alpha reductase inhibitors: dutasteride versus finasteride. Am J Manag Care. 2007;13(Suppl 1):S10-16

38. Fenter TC, Davis EA, Shah MB, et al. Dutasteride vs finasteride: assessment of differences in acute urinary retention rates and surgical risk outcomes in an elderly population aged $>$ or $=65$ years. Am J Manag Care. 2008;14(5 Suppl 2):S154-59.

39. Cindolo L, Berardinelli F, Fanizza C, et al. Clinical effects and economical impact of dutasteride and finasteride therapy in Italian men with LUTS. Arch Ital di Urol e Androl. 2013;85(4):200-06.

40. Fenter TC, Runken MC, Black L, et al. Finasteride versus dutasteride: a real-world economic evaluation. Am J Manag Care. 2007;13(Suppl 1):S23-28. 41. Naslund M, Eaddy MT, Kruep EJ, et al. Cost comparison of finasteride and dutasteride for enlarged prostate in a managed care setting among Medicare-aged men. Am J Manag Care. 2008;14(5 Suppl 2):S167-71.

42. Nickel JC, Gilling P, Tammela TL, et al. Comparison of dutasteride and finasteride for treating benign prostatic hyperplasia: the Enlarged Prostate International Comparator Study (EPICS). BJU Int. 2011;108(3):388-94.

43. Jeong YB, Kwon KS, Kim SD, et al. Effect of discontinuation of 5alphareductase inhibitors on prostate volume and symptoms in men with BPH: a prospective study. Urology. 2009;73(4):802-06.

44. Kim W, Jung JH, Kang TW, et al. Clinical effects of discontinuing 5 -alpha reductase inhibitor in patients with benign prostatic hyperplasia. Korean J Urol. 2014;55(1):52-56. 
APPENDIX Association Between Baseline Covariates and Treatment Estimated Using a Logistic Regression Model ${ }^{a}$

\begin{tabular}{|c|c|c|c|}
\hline & Odds Ratio & $95 \%$ CI & $P$ Value \\
\hline Age (per year) & 0.970 & $(0.964-0.976)$ & $<0.0001^{\mathrm{b}}$ \\
\hline \multicolumn{4}{|l|}{ Region (reference: North central) } \\
\hline Northeast & 0.835 & $(0.703-0.992)$ & $0.0398^{\mathrm{b}}$ \\
\hline South & 1.323 & $(1.163-1.506)$ & $<0.0001^{b}$ \\
\hline West & 0.819 & $(0.701-0.958)$ & $0.0123 \mathrm{~b}$ \\
\hline Unknown & 0.885 & $(0.399-1.964)$ & 0.7647 \\
\hline \multicolumn{4}{|l|}{ Insurance type (reference: comprehensive) } \\
\hline $\mathrm{HMO}$ & 0.423 & $(0.348-0.516)$ & $<0.0001^{b}$ \\
\hline POS & 0.708 & $(0.561-0.893)$ & $0.0036^{\mathrm{b}}$ \\
\hline $\mathrm{PPO}$ & 0.950 & $(0.827-1.090)$ & 0.4629 \\
\hline Other & 0.846 & $(0.637-1.123)$ & 0.2463 \\
\hline Unknown & 1.020 & $(0.740-1.407)$ & 0.9018 \\
\hline \multicolumn{4}{|l|}{ Year of index date (reference: 2010 ) } \\
\hline 2004 & 0.323 & $(0.170-0.614)$ & $0.0006^{b}$ \\
\hline 2005 & 0.705 & $(0.390-1.274)$ & 0.2469 \\
\hline 2006 & 1.374 & $(0.973-1.939)$ & 0.0713 \\
\hline 2007 & 1.529 & $(1.265-1.849)$ & $<0.0001^{b}$ \\
\hline 2008 & 1.489 & $(1.228-1.806)$ & $<0.0001^{\mathrm{b}}$ \\
\hline 2009 & 1.403 & $(1.171-1.682)$ & $0.0002^{\mathrm{b}}$ \\
\hline 2011 & 1.602 & $(1.358-1.891)$ & $<0.0001^{b}$ \\
\hline 2012 & 1.129 & $(0.929-1.372)$ & 0.2219 \\
\hline \multicolumn{4}{|l|}{ Index $\mathrm{AB}$ (reference: alfuzosin) } \\
\hline Doxazosin & 0.114 & $(0.081-0.159)$ & $<0.0001^{b}$ \\
\hline Tamsulosin & 0.715 & $(0.593-0.863)$ & $0.0005^{\mathrm{b}}$ \\
\hline Terazosin & 0.098 & $(0.071-0.137)$ & $<0.0001^{\mathrm{b}}$ \\
\hline Generic availability of finasteride (reference: no) & 0.818 & $(0.501-1.335)$ & 0.4211 \\
\hline \multicolumn{4}{|l|}{ I-PSS symptoms at baseline (reference: no) } \\
\hline Incomplete emptying & 1.023 & $(0.779-1.343)$ & 0.8725 \\
\hline Urinary frequency & 0.965 & $(0.794-1.172)$ & 0.7166 \\
\hline Urination intermittency & 0.657 & $(0.311-1.390)$ & 0.2719 \\
\hline Urination urgency & 0.958 & $(0.619-1.483)$ & 0.8487 \\
\hline Weak stream & 1.494 & $(1.042-2.142)$ & $0.0290^{b}$ \\
\hline Straining in urination & 1.317 & $(0.135-12.838)$ & 0.8126 \\
\hline Nocturia & 1.516 & $(1.193-1.926)$ & $0.0007^{b}$ \\
\hline \multicolumn{4}{|l|}{ BPH stage at baseline (reference: no BPH diagnosis) } \\
\hline 1.1 & 1.424 & $(1.272-1.595)$ & $<0.0001^{b}$ \\
\hline 1.2 & 1.138 & $(0.891-1.453)$ & 0.3008 \\
\hline 2.1 & 1.673 & $(0.995-2.815)$ & 0.0524 \\
\hline 2.2 & 0.827 & $(0.377-1.814)$ & 0.6363 \\
\hline 3.1 & 1.323 & $(0.794-2.203)$ & 0.2827 \\
\hline 3.2 & 0.917 & $(0.448-1.875)$ & 0.8115 \\
\hline 3.3 & 0.613 & $(0.053-7.105)$ & 0.6954 \\
\hline Quan-Comorbidity Index score (per point) & 0.992 & $(0.951-1.036)$ & 0.7219 \\
\hline \multicolumn{4}{|c|}{ Presence of specific conditions at baseline (reference: no) } \\
\hline Hematuria & 0.837 & $(0.713-0.983)$ & $0.0301^{\mathrm{b}}$ \\
\hline Bladder dysfunction & 0.783 & $(0.459-1.337)$ & 0.3707 \\
\hline Urinary incontinence & 0.813 & $(0.572-1.154)$ & 0.2462 \\
\hline Bladder stones & 0.875 & $(0.690-1.109)$ & 0.2698 \\
\hline Number of urologist visits (per visit) & 1.000 & $(0.998-1.002)$ & 0.6900 \\
\hline All-cause total cost (per $\$ 1,000)$ & 1.000 & $(1.000-1.000)$ & 0.0907 \\
\hline BPH-related total cost (per $\$ 1,000)$ & 1.000 & $(1.000-1.000)$ & 0.0928 \\
\hline \multicolumn{4}{|c|}{$\begin{array}{l}\text { aDutasteride vs. finasteride. } \\
\text { bP value }<0.05 \text {. } \\
\text { AB =alpha blocker; } B P H=\text { benign prostatic hyperplasia; } C I=\text { confidence interval; } H M O=\text { health maintenance organization; I-PSS=International Prostate Symptom Sco } \\
P O S=\text { point of service; } P P O=\text { preferred provider organization; }\end{array}$} \\
\hline
\end{tabular}

